\title{
Vertical particle fluxes dominate integrated multi-trophic aquaculture (IMTA) sites: implications for shellfish-finfish synergy
}

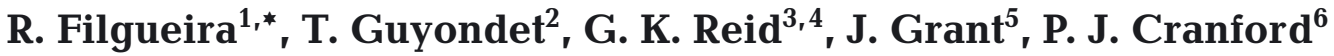 \\ ${ }^{1}$ Marine Affairs Program, Dalhousie University, 1355 Oxford St., PO Box 15000, Halifax, NS B3H 1R2, Canada \\ ${ }^{2}$ Department of Fisheries and Oceans, Gulf Fisheries Centre, Science Branch, PO Box 5030, Moncton, NB E1C 9B6, Canada \\ ${ }^{3}$ Canadian Integrated Multi-Trophic Aquaculture Network (CIMTAN), University of New Brunswick, PO Box 5050, \\ Saint John, NB E2L 4L5, Canada \\ ${ }^{4}$ Department of Fisheries and Oceans, St. Andrews Biological Station, 531 Brandy Cove Rd., St. Andrews, NB E5B 2L9, Canada \\ ${ }^{5}$ Department of Oceanography, Dalhousie University, Halifax, NS B3H 4R2, Canada \\ ${ }^{6}$ Department of Fisheries and Oceans, Bedford Institute of Oceanography, 1 Challenger Dr., Dartmouth, NS B2Y 4A2, Canada
}

\begin{abstract}
Maximizing the mitigation potential of open-water finfish-shellfish integrated multi-trophic aquaculture (IMTA) farms is complex in terms of co-locating the trophic components. Both the dispersal of finfish aquaculture wastes and biological processes are highly influenced by water circulation. Consequently, the evaluation of shellfish-finfish synergy requires a combined study of biological and physical processes, which can be achieved by the implementation and coupling of mathematical models. A highly configurable mathematical model was developed that can be applied at the apparent spatial scale of IMTA sites. The model tracks different components of the seston, including feed wastes, fish faeces, shellfish faeces, natural detritus and phytoplankton. Based on the characterization of these fluxes, a hypothetical IMTA site was used to explore different spatial arrangements for evaluating finfish-shellfish farm mitigation efficiency. The site was modelled following a factorial design, which tested 2 levels of background seston concentrations, 3 farm designs, 2 hydrodynamic conditions and 2 levels of aquaculture intensity. The model predicts that mitigation efficiency is highly dependent on the background environmental conditions, obtaining maximum mitigation under oligotrophic conditions that stimulate shellfish filtration activity. The dominance of vertical fluxes of particulate matter triggered by the high settling velocity of finfish aquaculture wastes suggests that suspended shellfish aquaculture cannot significantly reduce organic loading of the seabed. Consequently, this suggests that waste mitigation at IMTA sites should be best achieved by placing organic extractive species (e.g. deposit feeders) on the seabed directly beneath finfish cages rather than in suspension in the water column.
\end{abstract}

KEY WORDS: Settling velocity $\cdot$ Organic loading $\cdot$ Mitigation $\cdot$ Connectivity $\cdot$ Ecosystem model

\section{INTRODUCTION}

The projection of human population growth (United Nations, Department of Economic and Social Affairs, Population Division 2013) and the increasing demand

\footnotetext{
${ }^{*}$ Corresponding author: ramon.filgueira@dal.ca
}

for seafood per capita (FAO 2014) suggest an expansion in aquaculture activities in the coming decades. The rate of expansion will be driven by specific local pressures. For example, while social aspects such as aesthetics or conflict with other uses of the ocean will

(C) R. Filgueira, J. Grant and Fisheries and Oceans Canada 2017. Open Access under Creative Commons by Attribution Licence. Use, distribution and reproduction are unrestricted. Authors and original publication must be credited.

Publisher: Inter-Research · www.int-res.com 
probably dominate European and North American expansion, physical limits (e.g. space) on total production will most likely determine the fate of this expansion in Asia, where maximizing the food supply is the paramount concern (Ferreira et al. 2013). In between social and production concerns, ecological drivers play a significant role in this expansion because adverse ecosystem interactions can cause a negative feedback on both society and on the production potential (Stigebrandt 2011). Therefore, developing ecologically sustainable aquaculture will reduce negative societal pressures on this industry with concomitant economic benefits.

In the case of fed finfish aquaculture, one of the major ecological concerns is related to benthic organic loading (e.g. Strain \& Hargrave 2005). The vertical flux of uneaten feed and fish faeces can significantly alter sediment characteristics and communities, leading, in a worst-case scenario, to benthic oxygen depletion and local community impacts (Hargrave 2010). Dissolved nutrients are also released at fish farms and although they are quickly dispersed, they have been suggested to contribute to eutrophication (Sarà et al. 2011) and are the focus of regulations (Gillibrand et al. 2002). The ecologically engineered concept of integrated multi-trophic aquaculture (IMTA) uses a natural recycling approach across different trophic groups, where the by-products or wastes from one species become inputs for another within the same culture system (Chopin et al. 2012). Accordingly, the fed component (e.g. finfish) is combined with extractive species that recapture particulate organic matter (e.g. suspension- and deposit-feeders) and dissolved inorganic matter (e.g. seaweeds). In addition to potentially mitigating organic loading, the organic extractive species could benefit from the additional available food, potentially resulting in augmented growth and commercial benefits.

The capacity of an IMTA site to utilize wastes depends on: (1) the capacity of the extractive species to capture wastes, which is a function of its physiology, the amount of available wastes and the environmental conditions at the farm; and (2) the connectivity among the different components of the farm. Both factors are influenced by hydrodynamics, the spatial arrangement of extractive species and physicochemical properties of the wastes. Connectivity is crucial for increasing the probability of encounters between wastes and extractive species and is highly influenced by the settling velocity of the waste. For example, feed pellets sink directly beneath a fish cage but excreted ammonia remains in the water column. Regarding the capacity of the extractive species to capture wastes, it is important to highlight the role of the individual physiological response to environmental conditions, including the diet to which the individual is exposed. The mitigation capacity of the extractive species is proportional to the contribution of wastes to the naturally available food. That is, if wastes are diluted within naturally abundant food, wastes will not be a significant part of the extractive species' diet, which results in low mitigation. For example, it has been stated that 15 to $35 \%$ of the organic diet of mussels must be from fish farm particulates (faeces or feed 'fines') to significantly reduce net benthic organic loading, otherwise the organic loading generated by mussel faeces would be higher than the mitigation by capturing fish faeces (Cranford et al. 2013).

One of the key components in the historical and present design of IMTA systems is the use of bivalves as the main organic extractive species (Soto 2009). Given that bivalves are widely distributed, can be cultured at high densities and can severely deplete suspended particulate matter at the ecosystem scale, they are ideal candidates to be used as waste biofilters (Cranford et al. 2013). Despite this theoretically good fit between finfish and mussels in the context of IMTA farming, literature data reveal contradictory results. For example, some studies reported higher growth of IMTA bivalves compared to controls (Wallace 1980, Jones \& Iwama 1991, Stirling \& Okumus 1995, Troell \& Norberg 1998, Lander et al. 2004, 2012, Peharda et al. 2007, Sarà et al. 2009, 2012, Handå et al. 2012, Jiang et al. 2013) due to an increase in organic particles in the vicinity of finfish cages, but other studies showed little or no significant effects (Farias-Sánchez 1983, Taylor et al. 1992, Gryska et al. 1996, Parsons et al. 2002, Cheshuk et al. 2003, Navarrete-Mier et al. 2010, Irisarri et al. 2013). Rensel et al. (2011) highlighted interspecific differences under the same conditions in a case where oysters benefited from proximity to finfish cages whereas mussels did not. As Cranford et al. (2013) stated, it is difficult to compare the results of these studies to evaluate the ultimate cause of these discrepancies owing to the different experimental designs and environmental conditions. One of the key ways to evaluate whether mussels benefit from finfish wastes is to establish a reference site with identical environmental conditions so that IMTA mussels could be compared directly to reference mussels. However, natural environmental variability makes it difficult to define 2 identical sites that do not influence one another such that one of them could be used as a reference for comparison purposes (e.g. Brager et al. 2015). 
Mathematical modelling provides an opportunity to theoretically explore finfish-shellfish IMTA performance by means of comparing different 'what if' scenarios. Models have been used to explore a range of sustainability and/or management alternatives at aquaculture sites, including polyculture and IMTA sites (e.g. Duarte et al. 2003, Nunes et al. 2003, Ferreira et al. 2012, Ren et al. 2012). Numerical models allow for a detailed description of organic deposition and associated biogeochemical fluxes in finfish aquaculture sites. A model commonly applied to cage aquaculture for this purpose is DEPOMOD (Cromey et al. 2002), a Lagrangian particle-tracking model that predicts the spatial distribution of carbon deposition in the vicinity of the farm based on biodeposit production rates, current velocities and bathymetry. Other Lagrangian models (e.g. Jusup et al. 2007) predict organic loading and have been successfully coupled to other models to predict biogeochemical fluxes around fish cages (Brigolin et al. 2014). One of the most powerful capabilities of numerical models is the possibility of exploring different scenarios, which constitutes a critical aspect for management purposes (Nobre et al. 2010). For example, Tsagaraki et al. (2011) explored the effects of fish farming under different production levels and hydrodynamic conditions. These scenarios can even be coupled to economic models to analyse the profitability of an IMTA operation under different hydrodynamic scenarios (Ferreira et al. 2012). While different methodological approaches can be used for this purpose (Grant \& Filgueira 2011), a key aspect when evaluating the probability of encounter between waste and extractive species is spatial resolution. High spatial resolution is always desirable because it provides a more detailed description of the model domain. In addition, spatial resolution can also affect model predictions (Melbourne-Thomas et al. 2011), especially when the simulated processes are dependent on concentration (Fennel \& Neumann 2004). Consequently, in this study we developed 2 high-resolution fully spatial modelling approaches with the specific objectives of: (1) evaluating the maximum mitigation efficiency under different finfish-shellfish IMTA configurations (ecosystem model); and (2) exploring the fate of particles (feed waste and finfish faeces) released in finfish cages (particle-tracking model).

\section{MATERIALS AND METHODS}

\section{Model domain}

A hypothetical aquaculture site was used as a testing ground for the numerical experiments. Although the models that have been developed in this study can be applied to real case locations, the use of a hypothetical and ideal site is aligned with the main goal regarding the exploration of the maximum mitigation efficiency. Accordingly, this hypothetical site was constructed to maximize mitigation. This hypothetical site was defined using a structured triangular mesh that includes 1360 triangles and 718 nodes (Fig. 1). The dimensions of the model domain are $510 \mathrm{~m}$ long $\times 300 \mathrm{~m}$ wide and 15 or $30 \mathrm{~m}$ deep for the ecosystem and particle-tracking models, respectively. Although the bathymetry is important for determining the footprint of organic loading in the benthos, it is not relevant for estimating the mitigation efficiency of organic particles from shellfish culture, which is typically suspended within the top $15 \mathrm{~m}$ of the water column. Accordingly, bathymetry was not included in the factorial design to test mitigation.

\section{Ecosystem model}

The following 5 sources of organic carbon were modelled: fish feed waste (FW), fish faeces (FF), shellfish faeces (ShF), background detritus (D) and background phytoplankton (P). Only the unsettleable fraction of FW (feed 'fines') was modelled; the remaining organic material in FW (uneaten feed pellets) was assumed to sink directly to the bottom due
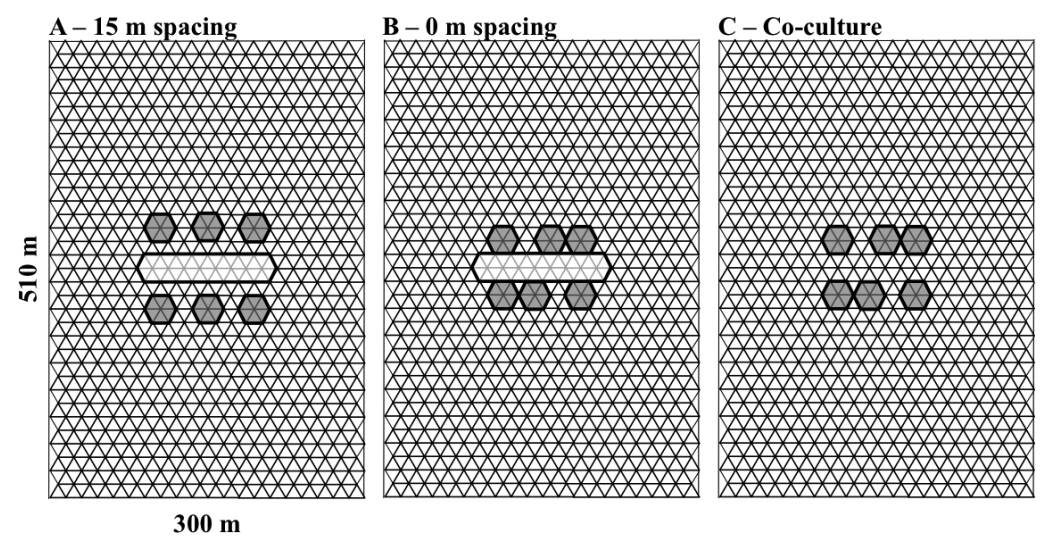

Fig. 1. Structured triangular mesh within the ecosystem model domain and the 3 farm designs studied: (A) $15 \mathrm{~m}$ separation, (B) $0 \mathrm{~m}$ separation and (C) co-culture. Dark and light grey hexagons represent finfish cages and shellfish longlines, respectively. In the co-culture design, finfish and shellfish are co-cultured together in the fish cages 
to high settling velocities. It is assumed that all particles are within the filtering size range of the shellfish and consequently they can be effectively captured. The term 'background' makes reference to the concentration of detritus or phytoplankton that would exist in the model domain in the absence of any aquaculture activity. All of the stocks were characterized in $\mathrm{mg} \mathrm{C} \mathrm{m}^{-3}$. The fluxes of the different particles were simulated according to the following equations coded in Matlab ${ }^{\circledR}$ (https://www.mathworks.com):

$$
\begin{aligned}
& \frac{\mathrm{dFW}}{\mathrm{d} t}=+\mathrm{FW}_{\text {production }}-\mathrm{Sh}_{\text {ingestion }} \pm \mathrm{FW}_{\text {mixing }} \\
& \frac{\mathrm{dFF}}{\mathrm{d} t}=+\mathrm{FF}_{\text {production }}-\mathrm{FF}_{\text {sinking }}-\mathrm{Sh}_{\text {ingestion }} \pm \mathrm{FF}_{\text {mixing }} \\
& \frac{\mathrm{dShF}}{\mathrm{d} t}=+\mathrm{Sh}_{\text {egestion }}-\mathrm{ShF}_{\text {sinking }}-\mathrm{Sh}_{\text {ingestion }} \pm \mathrm{ShF}_{\text {mixing }} \\
& \frac{\mathrm{dD}}{\mathrm{d} t}=+\mathrm{D}_{\text {production }}-\mathrm{D}_{\text {sinking }}-\mathrm{Sh}_{\text {ingestion }} \pm \mathrm{D}_{\text {mixingr }} \mathrm{D}_{\text {production }}=\mathrm{D}_{\text {sinking }} \\
& \frac{\mathrm{dP}}{\mathrm{d} t}=+\mathrm{P}_{\text {production }}-\mathrm{P}_{\text {sinking }}-\mathrm{Sh}_{\text {ingestion }} \pm \mathrm{P}_{\text {mixing' }} \mathrm{P}_{\text {production }}=\mathrm{P}_{\text {sinking }}
\end{aligned}
$$

where $t$ is time, 'production' represents the production of particles by aquaculture activities (FW, FF and $\mathrm{ShF}$ ) and natural processes (D and P); 'sinking' is the loss of particles due to sinking to the bottom following the average settling velocities depicted in Table 1; 'ingestion' is the ingestion of particles by shellfish; and 'mixing' is the exchange of particles among adjacent triangles. See the Supplement at www.int-res.com/articles/suppl/q009p127_supp.pdf for further details regarding the ecosystem model.

$\mathrm{FW}_{\text {production }}$ and $\mathrm{FF}_{\text {production }}$ rates were prescribed as constant forcing functions. This approach minimizes peaks in FW and FF, and better represents average conditions in the farm. This approach is less suitable for FW because feeding is not continuous through time. However, this simplification has a minimal impact on the available organic matter in the water column due to the small contribution of the unsettleable fraction of FW compared to other sources of organic matter such as FF (Table 2). Each finfish cage was characterized according to a typical mid-size farm in the Bay of Fundy (eastern Canada) area (see Reid et al. 2013a). The total feed was calcu-
Table 2. Different scenarios (constant forcing conditions) of background seston in terms of phytoplankton ( $\mathrm{P}, \mathrm{chl}$ a) and detritus (D, total seston) concentration, as well as farm production rate of fish faeces ( $\left.\mathrm{FF}_{\text {production }}\right)$ and unsettleable feed waste ( $\left.\mathrm{FW}_{\text {production }}\right)$

\begin{tabular}{|lccccc|}
\hline $\begin{array}{l}\text { Background } \\
\text { seston }\end{array}$ & $\begin{array}{c}\text { Farm } \\
\text { particles }\end{array}$ & $\begin{array}{c}\text { chl-a } \\
\left(\mu \mathrm{g} \mathrm{l}^{-1}\right)\end{array}$ & $\begin{array}{c}\text { Total seston } \\
\left(\mathrm{mg} \mathrm{l}^{-1}\right)\end{array}$ & $\begin{array}{c}\mathrm{FF}_{\text {production }} \\
\left(\mathrm{kg} \mathrm{d}^{-1} \mathrm{farm}^{-1}\right)\end{array}$ & $\begin{array}{c}\mathrm{FW}_{\text {production }} \\
\left(\mathrm{g} \mathrm{d}^{-1} \mathrm{farm}^{-1}\right)\end{array}$ \\
\hline Low & & 1.0 & 1.0 & & \\
Average & & 2.5 & 3.0 & & \\
High & & 4.0 & 5.0 & 15 & 35 \\
& Low & & & 25 & 70 \\
& Average & & & 35 & 105 \\
\hline
\end{tabular}

lated by taking into account Atlantic salmon Salmo salar biomass, growth rate and a feed conversion ratio of 1.2 (Reid 2007, Reid et al. 2013b). Fifteen percent of consumed fish feed was assumed to be $\mathrm{FF}_{\text {production }}$ and 3\% FW (Reid et al. 2009), of which $1.5 \%$ was assumed to be unsettleable $\left(\mathrm{FW}_{\text {production }}\right)$. It was assumed that $77 \%$ of FF ( $93 \%$ of FW) is organic and $38 \%$ of that ( $57 \%$ for $\mathrm{FW}$ ) is carbon (Reid et al. 2009 , 2010). $D_{\text {production }}$ and $P_{\text {production }}$ were set up equal in magnitude to $\mathrm{D}_{\text {sinking }}$ and $\mathrm{P}_{\text {sinking, }}$ respectively, in order to guarantee constant composition of the idealized ocean through time. Constant $P$ concentration was established in terms of $\mu \mathrm{g} \mathrm{chl} \mathrm{a} \mathrm{^{-1 }}$ (Table 2), and a C:chl a ratio of 50:1 was assumed to calculate organic carbon. Constant total seston concentration was established in terms of $\mathrm{mg} \mathrm{l}^{-1}$ (Table 2), of which $65 \%$ was assumed to be organic and, in turn, $50 \%$ of the organic fraction was assumed to be carbon. D concentration was calculated by subtracting $\mathrm{P}$ concentration from total organic carbon. Constant D and $\mathrm{P}$ values are intended to mimic average conditions in farming areas in the Bay of Fundy area (e.g. Brager et al. 2015).

The terms $\mathrm{Sh}_{\text {ingestion }}$ and $\mathrm{Sh}_{\text {egestion }}$ represent the ingestion of particles by shellfish and the production of faeces, respectively. The shellfish used in this study is Mytilus edulis, whose ecophysiology has been simulated by coupling a previously published dynamic energy budget (DEB) model (Filgueira et al. 
2011). See the Supplement for further details regarding the DEB model. DEB is coupled to the ecosystem model though $\mathrm{Sh}_{\text {ingestion }}$ and $\mathrm{Sh}_{\text {egestion, }}$ that is, ingestion of all the potential food sources and faeces production, respectively. Pumping rate $\left(\mathrm{PR}, \mathrm{l} \mathrm{h}^{-1}\right)$ is derived from DEB and multiplied by the concentration of a given particle, which results in $\mathrm{Sh}_{\text {ingestion. }}$. For each particle type, the multiplication of $\mathrm{Sh}_{\text {ingestion }} \times$ $\left(1-\right.$ absorption efficiency [Table 1]) provides $\mathrm{Sh}_{\text {egestion }}$. The parameters of the DEB model follow Filgueira et al. (2011) with the exception of 'absorption efficiency' which varied depending on the food particle (our Table 1, following Reid et al. 2010) and the 'scaled functional response', which was prescribed here as 1. This parameterization of the scaled functional response ensures that the mussels will ingest at maximum capacity. Given that ingestion is maximum at all times, the results will represent the maximum mitigation capacity, which is aligned with the main goal of the study. No pre-ingestive selection is considered in this version of the DEB model, so the specific removal of each kind of particle is proportional to the relative abundance of the organic carbon of that particle in relation to the total organic carbon. PR was calculated by taking into account the mussel's organic carbon ingestion rate and the concentration of organic carbon in the surrounding water. Given that it was assumed that all of the particles are $100 \%$ retained in the gills, PR is equivalent to clearance rate. The average density of farmed mussels was prescribed as $30 \mathrm{~kg} \mathrm{~m}^{-2}$ in terms of wet weight. The total ingestion and egestion of the population was extrapolated from the individual rates estimated by the DEB model. Given the relevance of PR in mitigation efficiency, both were selected as response variables to evaluate the performance under each tested scenario.

Mixing among adjacent cells was calculated following the protocol described by Filgueira et al. (2012), in which the velocity field is used as an external forcing to calculate transport following a firstorder upwind scheme. This results in an offline coupling scheme between the hydrodynamics and biogeochemical reactions. This protocol, also coded in Matlab ${ }^{\circledR}$, was coupled to the biogeochemical model. In this case, the velocity field was theoretically predefined following a semidiurnal cycle (Fig. 2). The bi-directional current direction always followed the longitudinal axis of the model domain. This set up maximizes the potential mitigation efficiency of the IMTA site because it maximizes the connectivity among finfish-shellfish structures, which is coherent with the goal of estimating maximum mitigation efficiency under optimal conditions (see above). Two

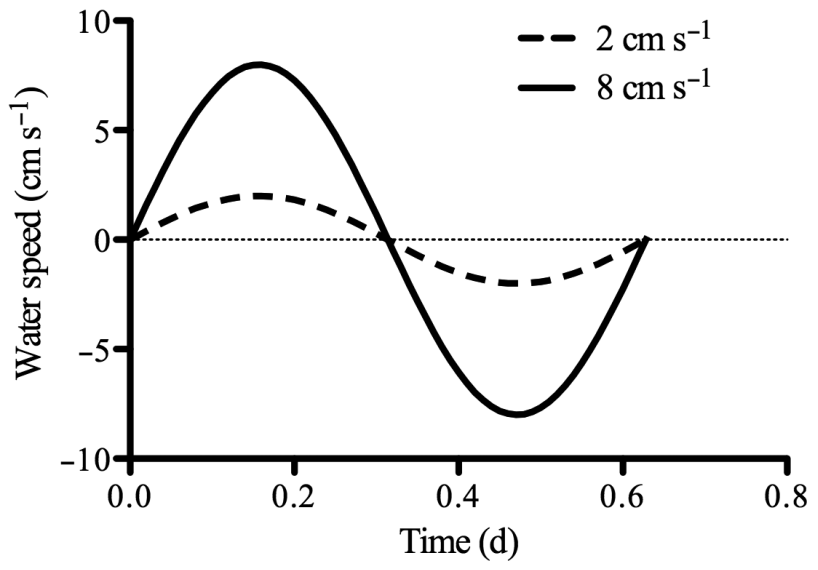

Fig. 2. Semidiurnal velocity patterns at the integrated multi-trophic aquaculture site tested in the factorial design experiment

potential scenarios with maximum horizontal water speed of 2 and $8 \mathrm{~cm} \mathrm{~s}^{-1}$ were defined, representing the minimum and maximum water speed at which a finfish aquaculture site can operate (values representative of typical Bay of Fundy facilities).

A factorial design was followed to explore different finfish-shellfish IMTA configurations. The following 3 farm designs were tested:

(1) 2 rows of 3 finfish cages separated by a central shellfish farm at $15 \mathrm{~m}$ distance from each row $(15 \mathrm{~m}$ spacing; Fig. 1A);

(2) the same design but with no spacing between fish pens and mussel structures (0 m spacing, Fig. 1B); and

(3) co-culture of finfish and shellfish inside the fish pens (co-culture; Fig. 1C). Note that the total area available for mussel culture in this design is slightly larger than for the other 2 designs. Consequently, the density of mussels was reduced to have the same biomass of extractive species in all designs.

For each of the 3 farm designs, the 2 velocity fields (Fig. 2) were tested and 2 different levels of background P and D were used (Table 2, low and high), which represent oligo- and eutrophic conditions. In addition, 2 levels of particle production, $\mathrm{FF}_{\text {production }}$ and $\mathrm{FW}_{\text {production, }}$ were considered (Table 2, high and low) that represent extreme husbandry practices. This factorial design gives a total of 24 scenarios. In addition, average conditions in terms of background and farm production levels were run for the different farm designs and hydrodynamic regimes (Table 2). Accordingly, the total number of tested scenarios reached 30.

The model was run for 2 tidal cycles (1.66 d) using a time step of $0.00001 \mathrm{~d}$. Data were recorded every $0.01 \mathrm{~d}$, but the first tidal cycle was discarded to mini- 
mize the impact of prescribing the homogeneous initial conditions across the model domain. The model was forced at the open boundaries with constant values of FW, FF, D and P, whose values change according to the different scenarios (Table 2). ShF was assumed to be negligible far from the mussel structures and consequently prescribed as 0 at the boundary. The velocity field was also prescribed as external forcing and assumed to be homogenous across the whole model domain. The velocity field followed Fig. 2 for the different hydrodynamic scenarios. The initial conditions of $\mathrm{D}$ and $\mathrm{P}$ were assumed to be homogeneous across the model domain (Table 2 for each scenario). Initial values of $\mathrm{FF}, \mathrm{FW}$ and $\mathrm{ShF}$ across the domain were set up as $0 \mathrm{mg} \mathrm{C} \mathrm{m}^{-3}$.

A sensitivity test was carried out in the scenarios that reported maximum mitigation efficiency for each farm design to explore the impact of settling velocity on modelling outcomes. The sensitivity test was performed by increasing and decreasing the settling velocity of FF by $10 \%$ and recording the change in mitigation efficiency.

\section{Particle tracking model}

This model used the same grid as the ecosystem model and was run only for the $15 \mathrm{~m}$ spacing farm design scenario (Fig. 1A). The water depth was increased to $30 \mathrm{~m}$ to describe full particle trajectories up to and beyond the maximum depth of the mussel structures $(15 \mathrm{~m})$. The 3-dimensional finite-volume model FVCOM (Chen et al. 2003, 2007, Cowles et al. 2008) was applied to estimate water flows over the domain using a $1 \mathrm{~m}$ vertical resolution. The model was also modified according to $\mathrm{Wu}$ et al. (2014) to incorporate the effect of fish cage drag on water circulation. From the 2 water flow scenarios, only the $8 \mathrm{~cm} \mathrm{~s}^{-1}$ amplitude (Fig. 2) was tested here as it maximizes the connectivity between fish and shellfish farms for the $15 \mathrm{~m}$ spacing design. A $2 \mathrm{~d}$ spin-up period was used to ramp up the system from initial still conditions.

A Lagrangian particle tracking module was coupled to the hydrodynamic engine (Foreman et al. 2015) to reproduce fish waste trajectories in response to water flow and settling velocity. Thirty categories of settling velocity were considered, ranging from 0.1 to $3 \mathrm{~cm} \mathrm{~s}^{-1}$. The different types of particles are identified by their average settling velocity (Table 1 ). The initial position of particles was randomly chosen inside each fish cage and both in the vertical and horizontal. Particles were released every $30 \mathrm{~min}$ over the first $12 \mathrm{~h}$ of an experiment to cover the tidal cycle variability. Each particle was then followed for at least $24 \mathrm{~h}$.

At each release time, 10 particles of each settling velocity category were introduced in each fish cage, amounting to a total of 43200 particles per experiment or 1440 particles per settling velocity category. The experiment was repeated 3 times with different initial release locations such that probability analyses were performed on 4320 trajectories for each settling velocity category. Each trajectory was analysed to record whether the particle entered the mussel farm. In the affirmative, the depth at which the particle entered the farm was also recorded.

\section{RESULTS AND DISCUSSION}

\section{Shellfish PR and mitigation efficiency}

As noted in the introduction, the most relevant drivers of mitigation potential of suspended shellfish in an IMTA are (1) the connectivity between the supply of wastes from finfish cages and the location of the shellfish, and (2) shellfish physiology, namely $\mathrm{PR}$, which ultimately will determine ingestion rate and consequently waste extraction capacity. The blue mussel Mytilus edulis was selected as the extractive species due to its wide distribution and filtration capacity. Mussels can be stocked at high densities, which, in combination with their PR, result in a high extraction capacity compared to other species, e.g. oysters (Filgueira et al. 2013). Therefore, mussels are ideal to test our main goal, that is, to evaluate the maximum mitigation efficiency under different finfish-shellfish IMTA configurations. The mussel DEB model determines the physiological response under different conditions in this numerical experiment. Mussel pumping activity was assumed to be physiologically controlled to maximize the ingestion of organic material (Winter 1976), with negligible food selection and rejection as pseudofaeces. Although food selection can take place at particle concentrations under the tested environmental conditions, more significant selectivity usually occurs at higher particle concentrations (>10 $\mathrm{mg} \mathrm{l}^{-1}$; Hawkins et al. 1998, 1999). These assumptions trigger maximum $P R s$ under low background seston conditions (Fig. 3). Under these seston conditions, the contribution of finfish particles causes a minimal effect on pumping rate, although pumping rate is always slightly higher at low versus high production of finfish particles (Fig. 3). Therefore, low seston environments would promote the best conditions for mitigation potential through 


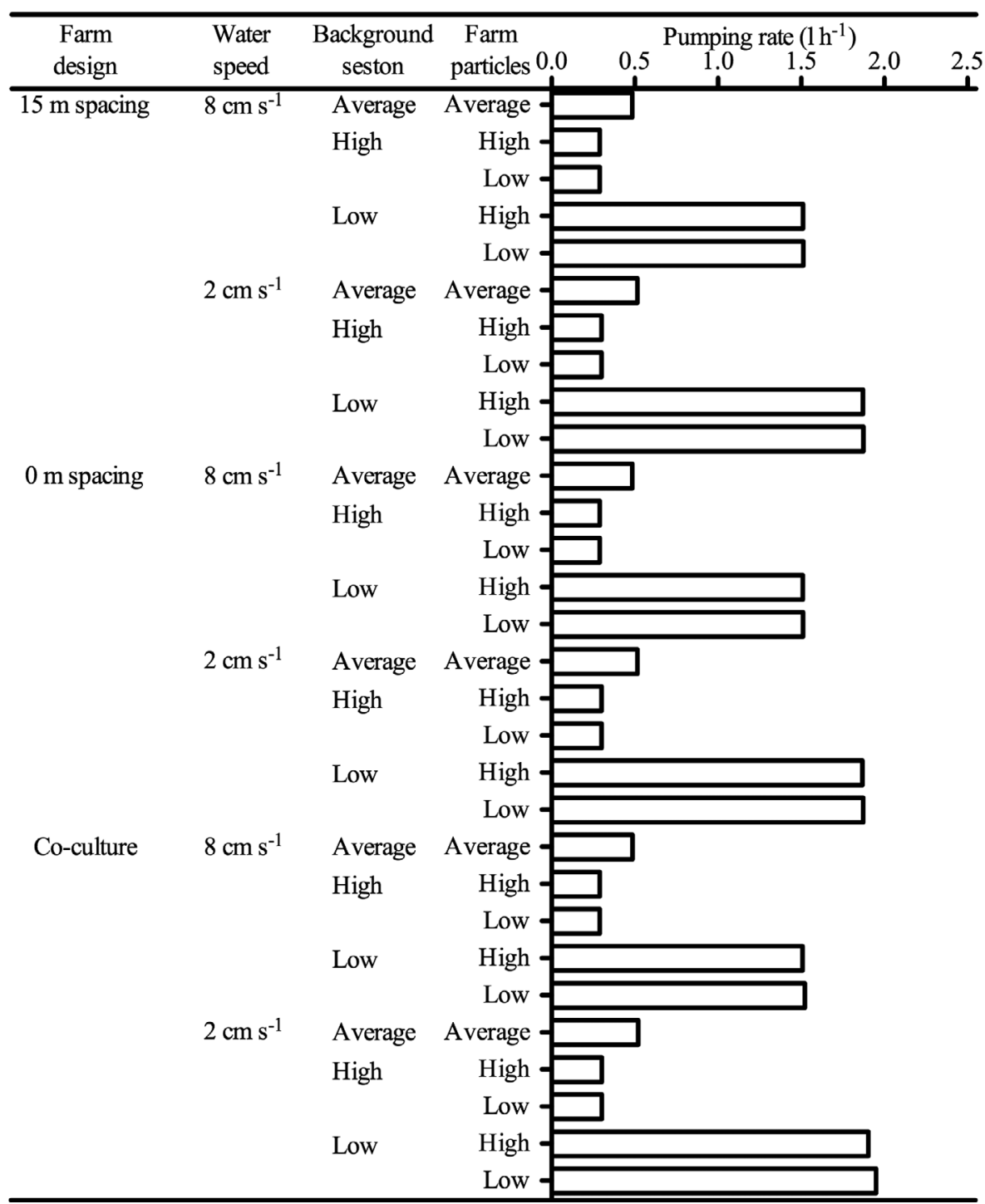

Fig. 3. Mussel pumping rate, standardized to a $60 \mathrm{~mm}$ shell length animal, in different scenarios defined in terms of farm design, water speed, background seston and production of particles in finfish cages

the stimulation of pumping activity and the relatively high contribution of wastes to the shellfish diet (Troell \& Norberg 1998, Cranford et al. 2013, Irisarri et al. 2014).

For identical trophic conditions of background seston and farm particle load, and independently of farm design, the regime with low water speeds, $2 \mathrm{~cm}$ $\mathrm{s}^{-1}$, promotes higher mussel PRs than high water speeds, $8 \mathrm{~cm} \mathrm{~s}^{-1}$ (Fig. 3). This is caused by the lower advection of background seston under the low water speed regime due to reduced horizontal flux and increased sinking, which decreases seston availability at the shellfish longline scale. This reduction in available organic material stimulates PRs in order to maximize organic ingestion. The design of the IMTA farm is not a significant factor for mussel PR since similar pumping values are observed independently of the relative positioning of longlines to finfish cages (Fig. 3). This result suggests that environmental conditions, namely background seston levels, dominate the ecophysiological response of the extractive species rather than the design of the IMTA site. This is consistent with observations by Irisarri et al. (2014) in Ría de Ares-Betanzos (Galicia, Spain), which showed that $M$. galloprovincialis in 2 locations at different distances from finfish cages reported similar clearance rates, and similar scope for growth.

Waste mitigation efficiency was evaluated as the percentage of FF ingested by mussels, which is analogous to an exploitation efficiency used to describe 
134

Aquacult Environ Interact 9: 127-143, 2017

resource acquisition in natural systems. This concept integrates the connectivity among IMTA structures and shellfish physiology, and it should not be understood as the net mitigation in terms of organic loading, which must include the contribution of ShF (Cranford et al. 2013). The combination of high PRs at low background sexton, low production of particles by finfish cages (Fig. 3) and the strong connectivity that results from the co-culture of finfish and shellfish under a low current regime triggered a maximum mitigation efficiency of $6.6 \%$ (Fig. 4). The comparison of Figs. 3 \& 4 highlights that high PRs are needed for greater mitigation efficiency, but the connectivity between finfish cages and shellfish longlines is also critical. The use of a hypothetical bidirectional velocity field along the north-south axis maximizes the connectivity among IMTA structures and conequently mitigation efficiency. Accordingly, any deviation in the field from that velocity field would cause a decrease in mitigation efficiency. Nevertheless, the simulations suggest that the highest connectivity is obtained under the co-culture design at low water speed regimes, $2 \mathrm{~cm} \mathrm{~s}^{-1}$. Under these conditions, FF are accessible for shellfish and consequently mitigatimon efficiency is increased. The increase of water speed to $8 \mathrm{~cm} \mathrm{~s}^{-1}$ in this farm configuration more rapidly flushes FF out of the cultivation area, reducing connectivity among IMTA species and consequently

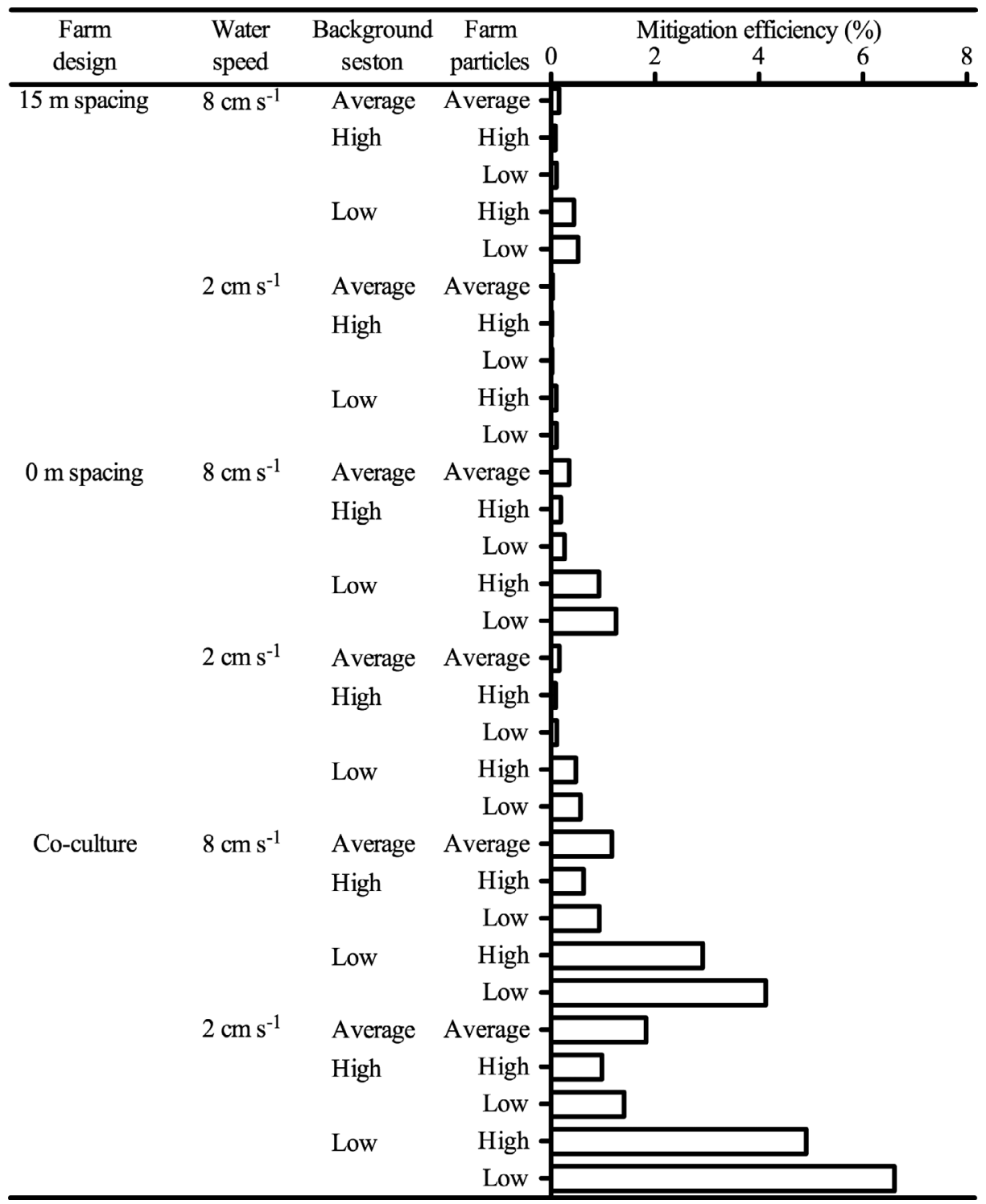

Fig. 4. Mitigation efficiency (percentage of produced fish faeces that have been ingested by mussels) in different scenarios defined in terms of farm design, water speed, background sexton and production of particles in finfish cages 
causing a reduction in mitigation efficiency (Fig. 4). The role of water currents in delivering particles is obvious when comparing the co-culture design with the other 2 configurations in which the mussels are farther from the source of faeces. In the $15 \mathrm{~m}$ and $0 \mathrm{~m}$ spacing designs, the increase in water currents enhances the delivery of wastes to the extractive species, consequently increasing mitigation efficiency, while the opposite occurs for co-culture (Fig. 4). These results are in good agreement with other observations and estimations that suggest that water currents have a direct impact on the concentration of wastes that exit finfish cages and consequently are available for integrated shellfish (Troell \& Norberg 1998).

The effect of current speed on mitigation efficiency is strongly related to settling velocity of wastes. Due to the high settling velocity of FF, $3 \mathrm{~cm} \mathrm{~s}^{-1}$ (Table 1), the amount of time that the wastes are in suspension and consequently available as food source for mussels is limited. The relatively high current speed in the $15 \mathrm{~m}$ and $0 \mathrm{~m}$ spacing designs allow a greater proportion of FF to travel from cages to shellfish longlines before sinking and becoming unavailable. Despite the increase in mitigation efficiency at high current speeds, mitigation efficiency for $15 \mathrm{~m}$ and $0 \mathrm{~m}$ spacing designs is always below 0.55 and $1.25 \%$, respectively, far from the $6.6 \%$ observed in coculture, suggesting that settling velocity is key for determining the connectivity among IMTA structures and consequently mitigation potential. These low values match other predictions in the literature. Ferreira et al. (2012) suggested that the typical IMTA configurations in North America and Europe, equivalent to the one tested in this study, do not normally allow detection of concentration changes for particu- late organic matter (POM) or chlorophyll in the field. Ferreira et al. (2012) studied these changes through modelling, and according to their Fig. 8, IMTA can reduce $\mathrm{POM}$ as much as $2.5 \%$ compared to a scenario with only fish (at the western boundary of the studied aquaculture park).

The sensitivity test demonstrated that the model is very sensitive to the settling velocity of FF. A change of $\pm 10 \%$ in this parameter always produces changes greater than $10 \%$ in mitigation efficiency (Fig. 5). The response in mitigation efficiency follows the same pattern in the 3 farm designs (Fig. 5), that is, a reduction in settling velocity keeps the particles in suspension for longer, allowing the mussels more time to feed on FF. This effect is relatively more important when mussel farms are far away from the source of FF (Fig. 5), further demonstrating that settling velocity is key to understand the connectivity among IMTA structures. The reduction in settling velocity and the concomitant increase in mitigation efficiency matches the hypothesis of Cranford et al. (2013), who suggested that the available time to trap wastes is one of the critical limitations in finfishshellfish IMTA mitigation potential.

\section{Fluxes of matter in IMTA sites}

The hydrodynamic-biogeochemical coupled model allows for the spatially explicit analysis of all of the IMTA particles in the water column at each time step. This facilitates the interpretation of fluxes of matter and understanding of spatial connectivity. For example, the normalized distribution of FF in the model domain at peak water speed in both hydrodynamic

\begin{tabular}{|c|c|c|c|c|}
\hline Farm & Water & Change in finfish & Mitigation efficiency (\%) & \\
\hline design & speed & faeces settling velocity 0 & $\begin{array}{llll}2 & 4 & 6 & 8\end{array}$ & 10 \\
\hline \multirow[t]{3}{*}{$15 \mathrm{~m}$ spacing } & $8 \mathrm{~cm} \mathrm{~s}^{-1}$ & $+10 \%$ & & $\overline{(-17.0 \%)}$ \\
\hline & & Average settling & & \\
\hline & & $-10 \%$ & & $(+22.7 \%)$ \\
\hline \multirow[t]{3}{*}{$0 \mathrm{~m}$ spacing } & $8 \mathrm{~cm} \mathrm{~s}^{-1}$ & $+10 \%$ & & $(-14.5 \%)$ \\
\hline & & Average settling & & \\
\hline & & $-10 \%$ & & $(+18.2 \%)$ \\
\hline \multirow[t]{3}{*}{ Co-culture } & $2 \mathrm{~cm} \mathrm{~s}^{-1}$ & $+10 \%$ & & $(-10.2 \%)$ \\
\hline & & Average settling & & \\
\hline & & $-10 \%$ & & $(+12.1 \%)$ \\
\hline
\end{tabular}

Fig. 5. Sensitivity test of mitigation efficiency to the settling velocity of finfish faeces evaluated in the scenarios that reported the highest mitigation efficiency for each farm design. The values in brackets represent the relative change in mitigation efficiency compared to the scenario with average settling velocity 
regimes for the $15 \mathrm{~m}$ spacing scenario is presented in Fig. 6. Water speed in both tested hydrodynamic regimes ranges from -2 to +2 and -8 to $+8 \mathrm{~cm} \mathrm{~s}^{-1}$ (Fig. 2), but the time step presented in this figure represents the distribution at peak water speed. The distribution at peak velocity is the farthest distance that FF can travel from the cages before sinking to depths at which they are no longer accessible for mussel longlines $(15 \mathrm{~m})$. Given the effect of settling velocities on mitigation efficiency (Fig. 5), the distribution of FF with the settling velocities explored in the sensitivity test are also plotted in Fig. 6. The distribution of faeces explains the observations based on PRs regarding connectivity between finfish cages and mussel longlines: (1) high current regimes (Fig. 6A-C) favour the spreading of FF over a larger area than low current regimes (Fig. 6D-F), improving connec- tivity; and (2) low settling rates maintain the highest FF concentrations in the water column, which is evident when comparing Fig. 6A vs. $6 \mathrm{C}$ and $6 \mathrm{D}$ vs. $6 \mathrm{~F}$, favouring connectivity.

Even when selecting the scenario with the highest degree of connectivity (high currents and low settling velocities) (Fig. 6A), the concentration of FF at the mussel longlines is negligible compared to the concentration at the center of the cages. However, the existence of a plume of material exiting the finfish cages is critical for the emplacement of extractive species and exploitation of IMTA synergies (Reid et al. 2010). The low concentration of particles at the shellfish farm predicted in this study (Fig. 6) suggests that this theoretical plume is weak, which would explain the low mitigation efficiency (Fig. 4). Several studies have focused on the identification of this

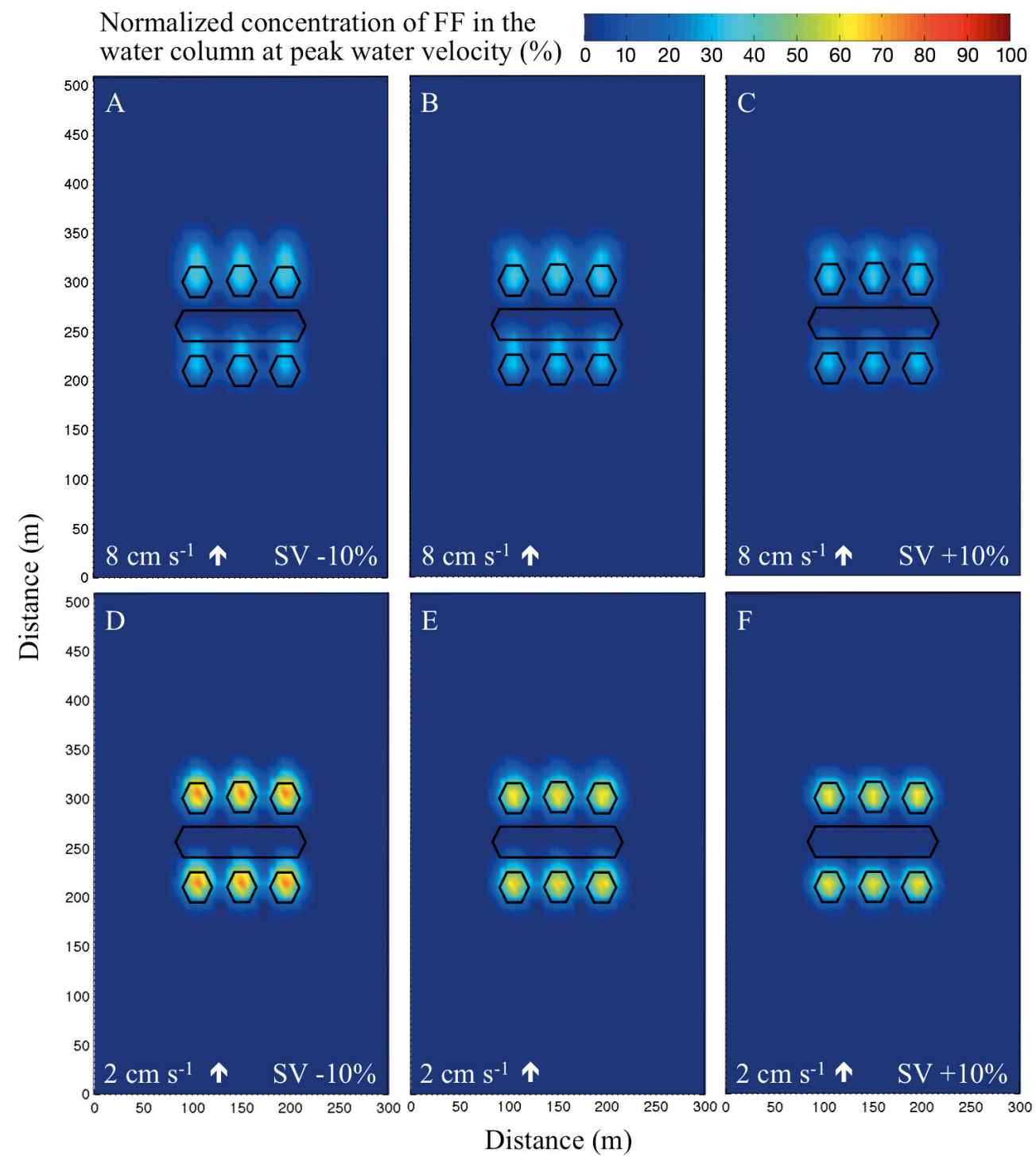

Fig. 6. Normalized concentration of finfish faeces $(\mathrm{FF}, \%)$ in the water column at the time step in which velocity is at maximum in the farm design with $15 \mathrm{~m}$ spacing (see Fig. 1) in both hydrodynamic regimes (A-C: high current, D-F: low current) for the 3 tested FF settling velocities (SV). The concentration of FF has been normalized to the maximum concentration across the 6 simulations for comparative purposes. The white arrow represents the direction of water currents at peak velocity 
waste plume, and the literature shows a degree of controversy. For example, Jones \& Iwama (1991), Lefebvre et al. (2000) and MacDonald et al. (2011) observed elevated particle concentrations around finfish cages, but Pridmore \& Rutherford (1992), Buschmann et al. (1996) and Cheshuk et al. (2003) did not observe significant enrichment. High-resolution suspended particle mapping around salmon pens in the Bay of Fundy occasionally detected low levels of particle enhancement $\left(<1 \mathrm{mg} \mathrm{l}^{-1}\right)$, with any significant effect being highly localized and episodic (Brager et al. 2015). Despite these confounding observations, there is a general consensus that shellfish should be placed as close as possible to finfish cages (Brown et al. 1987, Gowen \& Bradbury 1987, Gowen et al. 1988, Coyne et al. 1994, Findlay et al. 1995, Cheshuk et al. 2003, Lander et al. 2012, 2013, Brager et al. 2015) to avoid the strong dilution of the plume beyond the cage, which occurs beyond $10 \mathrm{~m}$ according to Lander et al. (2013). This placement requires a very specific design, such as the square cages used in British Columbia (Canada), where the bivalve extractive species can be located right beside the finfish cage, potentially benefiting from the additional organic matter (Weldrick \& Jelinski 2016). Another alternative arrangement that could benefit IMTA is the spatial design developed in some Chinese bays, such as Sanggou Bay, in which most of the available area is occupied by finfish, shellfish and seaweed farms (Fang et al. 2016 and references therein). However, this placement or spatial arrangement is not usually practical for logistical reasons in most of the farms elsewhere.
The fact that FF are maintained in suspension for only a limited time due to high settling velocity suggests that vertical fluxes dominate IMTA sites. Brager et al. (2015) also highlighted that several processes at the cage level such as turbulence, reduced flow due to baffling by the structures, biofouling and the presence of extracellular polymers can enhance particle aggregation and the vertical flux of fine particles. The vertical fluxes of organic carbon have been computed at $15 \mathrm{~m}$ depth, which is assumed to be close to the average depth of a finfish cage $(\sim 13 \mathrm{~m})$ and the maximum depth at which mussel culture is commonly carried out worldwide. Consequently, beyond that point, particles are assumed to be inaccessible to mussels. The normalized vertical flux of organic carbon over a tidal cycle is presented in Fig. 7 for the best scenarios in terms of mitigation efficiency for each farm design. The simulations strongly suggest that the highest vertical fluxes of organic matter in IMTA sites are located directly beneath finfish cages (Fig. 7). This is despite the fact that in these simulations the settleable fraction of feed wastes are not included because they cannot be mitigated by mussels given that (1) they sink directly to the bottom due to their even higher settling velocity, and (2) they are too big to be ingested by mussels. Although the final fate of the vertical flux of organic carbon at $15 \mathrm{~m}$ depth also depends on the total depth of the area (see below), these simulations strongly agree with other studies, which suggest that the impact of organic loading on finfish farms is restricted to the near-field (e.g. Brooks \& Mahnken 2003, Wildish et al. 2004, Chang et al. 2014). These results high-
Fig. 7. Normalized vertical flux of carbon towards the bottom at $15 \mathrm{~m}$ depth averaged over a tidal cycle for the best scenarios in terms of mitigation efficiency in the 3 farm designs (see Fig. 1): (A) $15 \mathrm{~m}$ separation, (B) $0 \mathrm{~m}$ separation and $(\mathrm{C})$ co-culture. The vertical flux of carbon was normalized to the maximum flux across the 3 simulations for comparative purposes

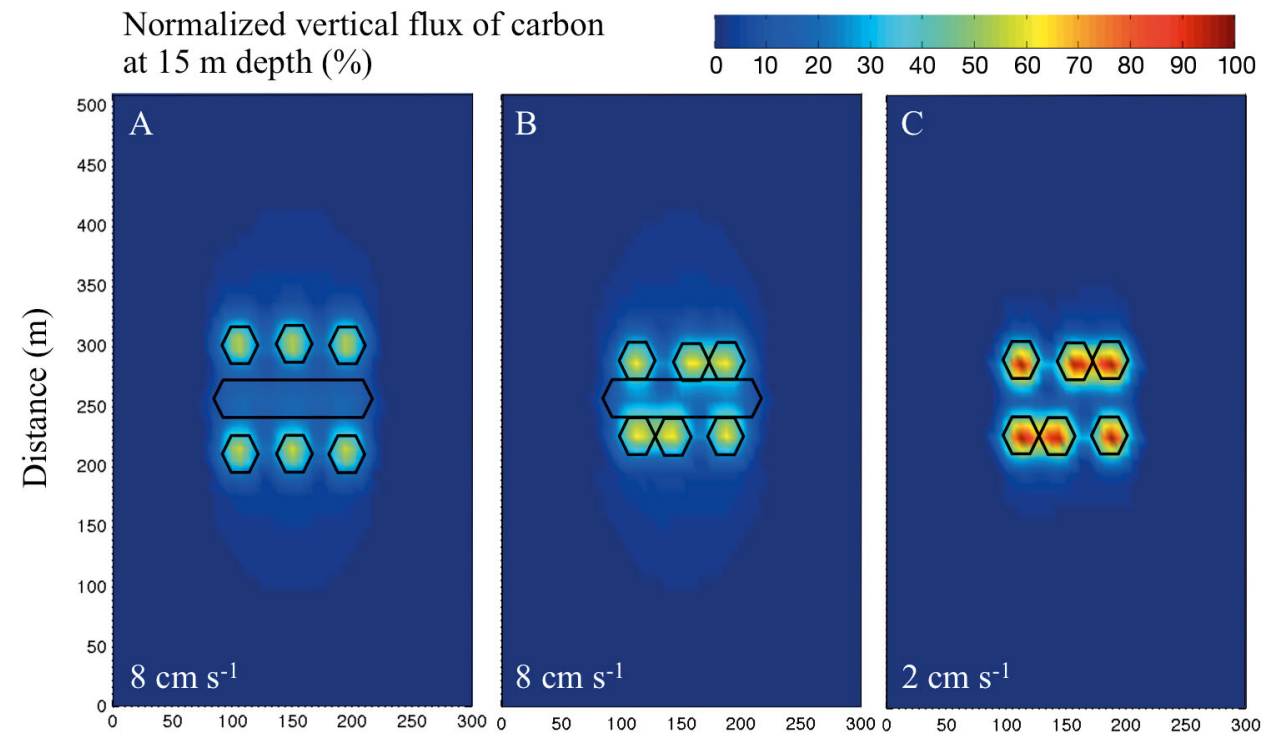

Distance (m) 
lighting the strong vertical fluxes are in good agreement with Cubillo et al. (2016) and suggest a limited usefulness of shellfish for mitigating solid wastes in IMTA sites using current technology and aquaculture practices.

The second significant conclusion that can be extracted from Fig. 7 is that despite the highest removal of FF in the co-culture scenario, the vertical flux of organic carbon is also highest in the co-culture scenario (Fig. 7C), suggesting that there is no net mitigation in terms of organic loading. The direct relationship between mitigation efficiency and the peak of vertical flux of organic carbon suggests that positive mitigation with FF close to mussels, is negative for organic loading due to faeces production by the extractive species. To overcome this limitation, Cranford et al. (2013) suggested that 15 to $35 \%$ of the organic matter that mussels consume should be from fish waste to significantly reduce net benthic organic loading and compensate for the new production of ShF. Following a similar approach, Reid et al. (2013a) suggested that depending on diet quality, 11 to $20 \%$ of total mussel diet must be comprised of fish farm solids, in order to reduce the site-wide organic load.

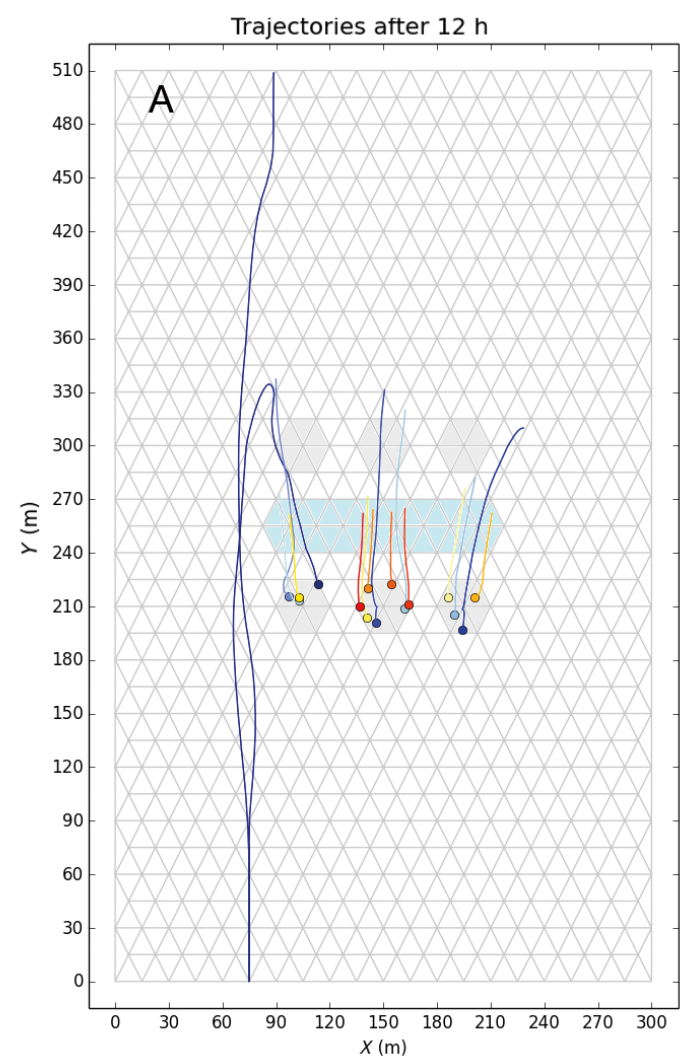

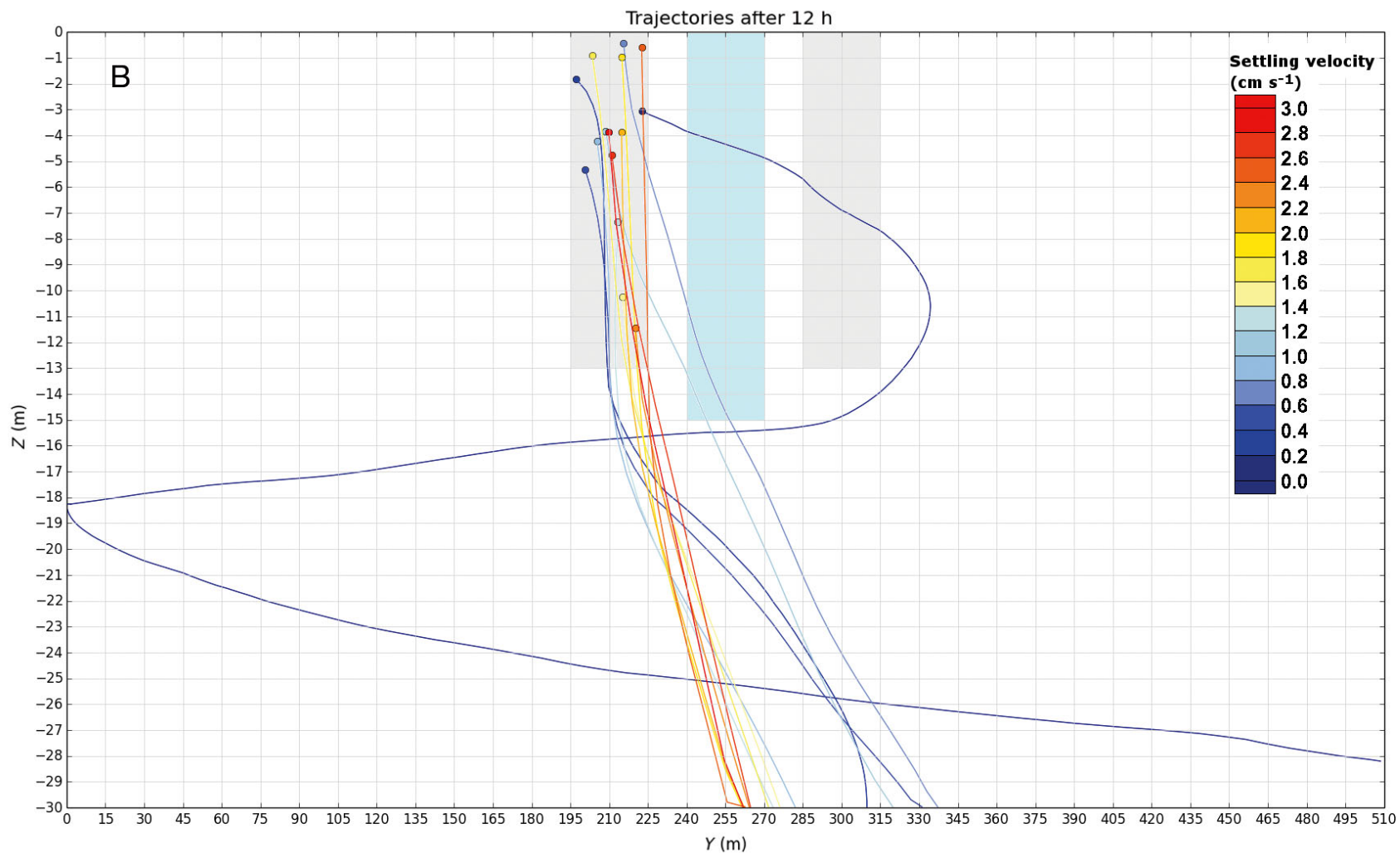

Fig. 8. (A) Plan view (transverse and longitudinal, $X$ and $Y$, respectively) and (B) vertical profile trajectories after $12 \mathrm{~h}$ of a subset of particles with different settling velocities released at random positions in 3 finfish cages (light grey). Mussel longlines are represented in light blue. Note that the vertical and horizontal scales ( $Z$ and $Y$, respectively) in (B) are different for 

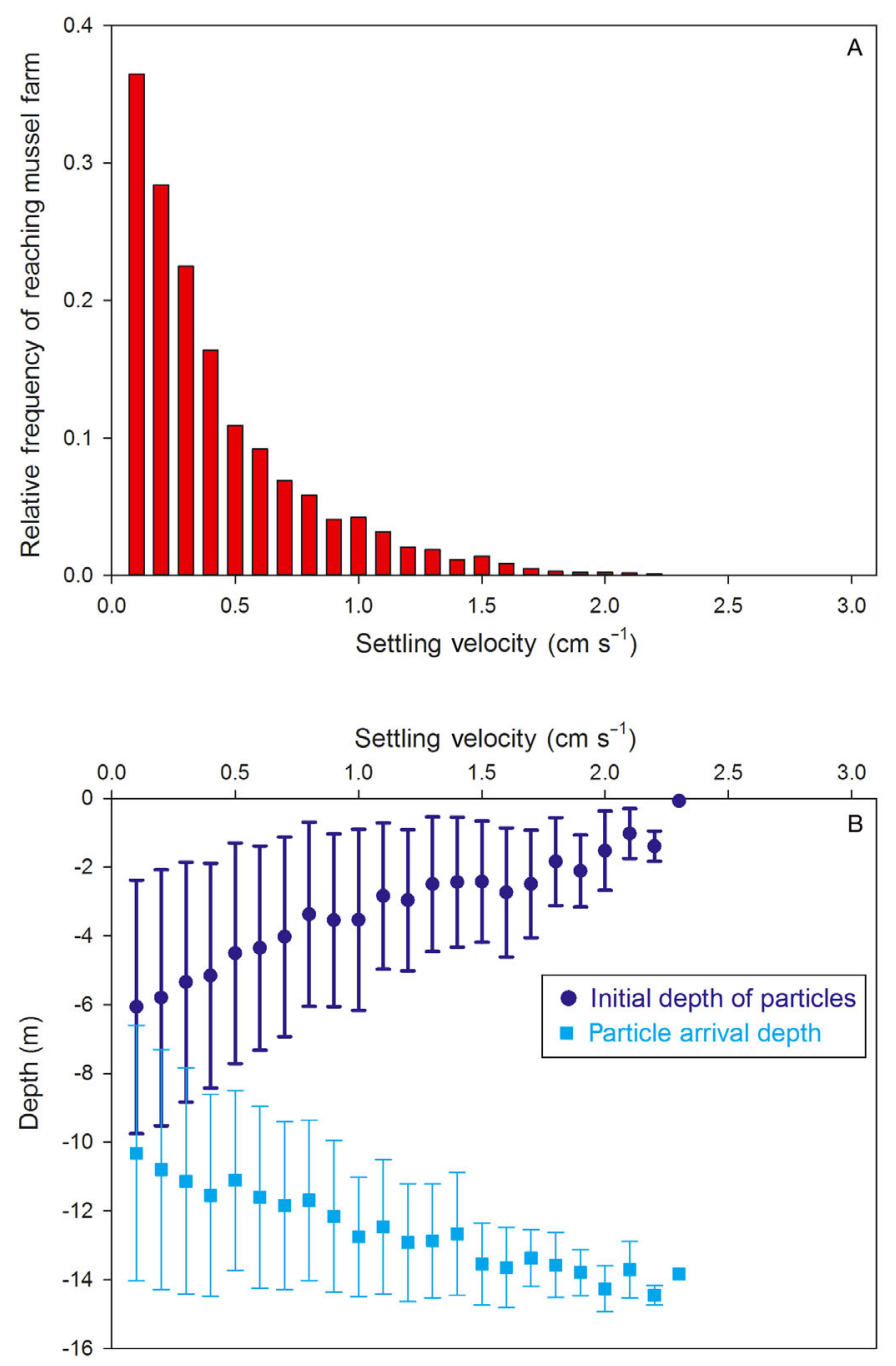

Fig. 9. (A) Probability of reaching the shellfish longlines for particles with different settling velocities released at finfish cages. (B) Mean $( \pm \mathrm{SD})$ depth at which these particles reach the shellfish longlines (squares) and mean $( \pm \mathrm{SD})$ initial depth of these particles at finfish cages (dots)

\section{Fate of particles with different settling velocities}

One of the key assumptions in the ecosystem model is that each particle type is characterized by averaged parameters and the fluxes are characterized in terms of concentration per time. However, it is well known that FF occur as a range of particle sizes and settling velocities. This conceptual simplification is needed in order to cope with the computational resources required to simulate a complex ecosystem. Nevertheless, this simplification can increase the uncertainty of modelling outcomes, especially when there is sensitivity to one of the parameters related to this simplifi- cation, i.e. settling velocity. In order to explore the effects of a range of settling velocities on the previous results calculated with averaged values, a different modelling exercise was carried out with focus on the physics of the wastes rather than on the biology. The particle tracking numerical experiment developed in FVCOM allowed a probabilistic analysis of finfishshellfish connectivity based on the analysis of the trajectories of particles with different settling velocities. In addition, FVCOM allows for the incorporation of the feedback of the aquaculture structures on local currents, that is, flow reduction, which provides a more realistic approach to horizontal fluxes. Fig. 8 presents an example of how FVCOM depicts horizontal and vertical trajectories after $12 \mathrm{~h}$ of a subset of particles with different settling velocities released at random positions inside 3 different finfish cages in the $15 \mathrm{~m}$ spacing design. This analysis (Fig. 8) provides a visual example of the impact of settling velocity on particle trajectory and probability for waste particles to reach the shellfish farm, showing that this probability increases for particles with low settling velocities while heavy particles tend to sink directly to the bottom in the proximity of the finfish cage.

The trajectories of 129600 particles $(43200 \times 3$ experiments) with different settling velocity released in the finfish cages were analysed with the aim of identifying the percentage of the particles that encountered the mussel farm (Fig. 9A). This probability exponentially decays with the settling velocity, reaching null probability at $2.4 \mathrm{~cm} \mathrm{~s}^{-1}$ (Fig. 9A). The results obtained with FVCOM partially disagree with the previous simulations carried out with the hydrodynamic-biogeochemical coupled model, which predicted that some FF $\left(\sim 3 \mathrm{~cm} \mathrm{~s}^{-1}\right.$, Table 1) could reach the shellfish farm under the same conditions (Fig. 6B). Although the set up of both simulations is conceptually similar, FF are parameterized as independent particles in FVCOM but as a concentration in the coupled model, which implies a different mathematical approach to transport. This can cause the partial disagreement. In addition, FVCOM accounts for flow reduction caused by farming structures, which is not included in the coupled model. Another source of differences is the vertical spatial resolution. The FVCOM model is constructed with $1 \mathrm{~m}$ thick layers, but the coupled model integrates $15 \mathrm{~m}$ in each layer with the aim of including the whole cage/longline in the same vertical layer in order to save computational resources. Despite the disagreement, both results confirm that heavy particles tend to settle to the bottom before reaching the shellfish farm. 
The fine vertical resolution of the FVCOM model also allows for an analysis of the depth at which particles reach the mussel farm. As expected, this depth increases with settling velocity from $\sim 10 \mathrm{~m}$ to $\sim 14 \mathrm{~m}$ for 0.1 and $2.4 \mathrm{~cm} \mathrm{~s}^{-1}$ particles, respectively (Fig. 9B). The degree of success in reaching the shellfish farm is highly dependent on the depth at which the particle is released (Fig. 9B). While the average initial depth of particles with settling velocity of $0.1 \mathrm{~cm} \mathrm{~s}^{-1}$ that successfully reach the mussel farm is $\sim 6 \mathrm{~m}$, the initial depth of the only particle with a settling velocity of $2.4 \mathrm{~cm} \mathrm{~s}^{-1}$ that reaches the shellfish cage is $\sim 0 \mathrm{~m}$ (Fig. 9B). This result matches previous observations and suggests that settling velocity and vertical fluxes dominate IMTA sites, and the connectivity between finfish cages and shellfish structures is highly dependent on positioning, suggesting that only structures that are very close together will be able to be effectively connected.

\section{CONCLUSIONS}

The modelling exercises performed in this study focussed on exploring the maximum mitigation efficiency of mussel-finfish IMTA sites, with focus on the solid wastes that potentially cause organic loading. These simulations were performed under ideal conditions that maximize the connectivity between finfish and shellfish cultured areas, e.g. ideal current directionality, and consequently it is expected that the mitigation efficiency estimations are maxima. Despite these ideal conditions that maximize mitigation, the models predicted low mitigation efficiencies, which is a direct consequence of the high settling velocity of finfish aquaculture wastes (faeces and feed), and the consequent dominance of strong vertical fluxes of organic material. A recent study by Bannister et al. (2016) provided a detailed analysis of settling velocity for different size classes of salmon, showing that the settling velocity of faecal particles is higher than $5 \mathrm{~cm} \mathrm{~s}^{-1}$ for more than $60 \%$, and higher than $2.5 \mathrm{~cm} \mathrm{~s}^{-1}$ for more than $80 \%$. Although faecal settling velocity is largely influenced by dietary ingredients (Reid et al. 2009), the results from Bannister et al. (2016) suggest that perhaps our study was very conservative in assuming that the average settling velocity is $3 \mathrm{~cm} \mathrm{~s}^{-1}$. This updated distribution of settling velocities and the results from our study reinforce the idea that vertical fluxes of organic matter are stronger than horizontal ones in finfish farms, which explain the weak plumes of wastes and limited connectivity among IMTA structures, critical for mitigation purposes (Reid et al. 2010). The potential for capturing solid wastes improves under specific conditions such as oligotrophic environments, and optimal spatial arrangements, but even in these situations, the net mitigation should be carefully explored because of the additional contribution of ShF to organic loading. In addition, other aspects should be considered to evaluate the viability of IMTA sites. For example, the co-culture design, despite being the one that maximizes the mitigation efficiency, is probably not viable at the commercial scale with the current technology. Other important aspects that would need additional research to evaluate the viability are the effects of the co-cultured species on disease transmission and the effect of chemicals such as medicines or pesticides on the co-cultured species. These interactions are poorly studied and could be critical at IMTA sites. In summary, and similarly to Cubillo et al. (2016), the low potential for mitigation suggests that shellfish suspended culture cannot significantly reduce organic loading. The dominance of vertical fluxes of organic material in finfish aquaculture suggests that organic extractive species in IMTA farms should be located in the benthic environment directly beneath finfish cages in order to maximize the mitigation of accumulated organic wastes. However, it is important to highlight that shellfish could indirectly mitigate organic loading by feeding on phytoplankton populations that could be enhanced due to the remineralization of organic loading and the excretion of nitrogen by fish. These positive effects should be analysed at the watershed scale. Further experimental and modelling studies with focus on the mitigation potential of deposit-feeders such as sea cucumbers will be key in evaluating the future of IMTA.

Acknowledgements. This research was funded by the Natural Sciences and Engineering Research Council of Canada (NSERC) Strategic Research Network titled Canadian Integrated Multi-Trophic Aquaculture Network (CIMTAN). Additional support was provided by an NSERC Industrial Research Chair to J.G.

\section{LITERATURE CITED}

Bannister RJ, Johnsen IA, Hansen PK, Kutti T, Asplin L (2016) Near- and far-field dispersal modelling of organic waste from Atlantic salmon aquaculture in fjord systems. ICES J Mar Sci 73:2408-2419

* Brager LM, Cranford PJ, Grant J, Robinson SMC (2015) Spatial distribution of suspended particulate wastes at open-water Atlantic salmon and sablefish aquaculture 
farms in Canada. Aquacult Environ Interact 6:135-149

Brigolin D, Meccia VL, Venier C, Tomassetti P, Porrello S, Pastres R (2014) Modelling biogeochemical fluxes across a Mediterranean fish cage farm. Aquacult Environ Interact 5:71-88

Brooks KM, Mahnken CVW (2003) Interactions of Atlantic salmon in the Pacific Northwest environment II. Organic wastes. Fish Res 62:255-293

* Brown JR, Gowen RJ, McLusky DS (1987) The effect of salmon farming on the benthos of a Scottish sea loch. J Exp Mar Biol Ecol 109:39-51

* Buschmann A, Troell M, Kautsky N, Kautsky L (1996) Integrated tank cultivation of salmonids and Gracilaria chilensis. Hydrobiologia 326-327:75-84

* Chang BD, Page FH, Losier RJ, McCurdy EP (2014) Organic enrichment at salmon farms in the Bay of Fundy, Canada: DEPOMOD predictions versus observed sediment sulfide concentrations. Aquacult Environ Interact 5:185-208

Chen C, Liu H, Beardsley RC (2003) An unstructured grid, finite-volume, three-dimensional, primitive equations ocean model: application to coastal ocean and estuaries. J Atmos Ocean Technol 20:159-186

* Chen C, Huang H, Beardsley RC, Liu H, Xu Q, Cowles G (2007) A finite volume numerical approach for coastal ocean circulation studies: comparisons with finite difference models. J Geophys Res 112:C03018

* Cheshuk BW, Purser GJ, Quintana R (2003) Integrated open-water mussel (Mytilus planulatus) and Atlantic salmon (Salmo salar) culture in Tasmania, Australia. Aquaculture 218:357-378

* Chopin T, Cooper JA, Reid G, Cross S, Moore C (2012) Open-water integrated multi-trophic aquaculture: environmental biomitigation and economic diversification of fed aquaculture by extractive aquaculture. Rev Aquacult $4: 209-220$

Cowles GW, Lentz SJ, Chen C, Xu Q, Beardsley RC (2008) Comparison of observed and model-computed low frequency circulation and hydrography on the New England Shelf. J Geophys Res 113:C09015

* Coyne R, Hiney M, O'Connor B, Kerry J, Cazabon D, Smith $P$ (1994) Concentration and persistence of oxytetracycline in sediments under a marine salmon farm. Aquaculture 123:31-42

Cranford PJ, Reid GK, Robinson SMC (2013) Open water integrated multi-trophic aquaculture: constraints on the effectiveness of mussels as an organic extractive component. Aquacult Environ Interact 4:163-173

* Cromey CJ, Nickell TD, Black KD (2002) DEPOMOD-modeling the deposition and biological effects of waste solids from marine cage farms. Aquaculture 214:211-239

Cubillo AM, Ferreira JG, Robinson SMC, Pearce CM, Corner RA, Johansen J (2016) Role of deposit feeders in integrated multi-trophic aquaculture - a model analysis. Aquaculture 453:54-66

* Duarte P, Meneses R, Hawkins AJS, Zhu M, Fang J, Grant J (2003) Mathematical modelling to assess the carrying capacity for multi-species culture within coastal waters. Ecol Model 168:109-143

Fang J, Zhang J, Xiao T, Huang D, Liu S (2016) Integrated multi-trophic aquaculture (IMTA) in Sanggou Bay, China. Aquacult Environ Interact 8:201-205

FAO (Food and Agriculture Organization of the United Nations) (2014) The state of world fisheries and aquaculture. FAO, Rome

Farias-Sánchez JA (1983) Experimental trial on the growth of mussels, Mytilus edulis, on ropes suspended from marine fish cages. MSc thesis, University of Stirling

Fennel W, Neumann T (2004) Introduction to the modelling of marine ecosystems. Elsevier Oceanography Series, 72. Elsevier, Amsterdam

Ferreira JG, Saurel C, Ferreira JM (2012) Cultivation of gilthead bream in monoculture and integrated multi-trophic aquaculture. Analysis of production and environmental effects by means of the FARM model. Aquaculture 358-359:23-34

Ferreira JG, Grant J, Verner-Jeffreys DW, Taylor NGH (2013) Carrying capacity for aquaculture, modeling frameworks for determination of. In: Christou P, Savin R, Costa-Pierce B, Misztal I, Whitelaw B (eds) Sustainable food production. Springer Science+Business Media, New York, NY, p 417-448

* Filgueira R, Rosland R, Grant J (2011) A comparison of scope for growth (SFG) and dynamic energy budget (DEB) models applied to the blue mussel (Mytilus edulis). J Sea Res 66:403-410

Filgueira R, Grant J, Bacher C, Carreau M (2012) A physicalbiogeochemical coupling scheme for modeling marine coastal ecosystems. Ecol Inform 7:71-80

Filgueira R, Comeau LA, Landry T, Grant J, Guyondet T, Mallet A (2013) Bivalve condition index as an indicator of aquaculture intensity: a meta-analysis. Ecol Indic 25: 215-229

Findlay RH, Watling L, Mayer LM (1995) Environmental impact of salmon net-pen culture on marine benthic communities in Maine: a case study. Estuaries 18: 145-179

Foreman MGG, Chandler PC, Stucchi DJ, Garver KA, Guo M, Morrison J, Tuele D (2015) The ability of hydrodynamic models to inform decisions on the siting and management of aquaculture facilities in British Columbia. Canadian Science Advisory Secretariat Research Document 2015/005, Department of Fisheries and Oceans Canada, Ottawa

Gillibrand PA, Gubbins MJ, Greathead C, Davies IM (2002) Scottish executive locational guidelines for fish farming: predicted levels of nutrient enhancement and benthic impact. Scottish Fisheries Research Report Number $63 / 2002$

Gowen RJ, Bradbury NB (1987) The ecological impact of salmonid farming in coastal waters: a review. Oceanogr Mar Biol Annu Rev 25:563-575

Gowen RJ, Brown J, Bradbury NB, McLusky DS (1988) Investigations into benthic enrichment, hypernutrification and eutrophication associated with mariculture in Scottish coastal waters. J Exp Mar Biol Ecol 109:39-51

Grant J, Filgueira R (2011) The application of dynamic modelling to prediction of production carrying capacity in shellfish farming. In: Shumway S (ed) Shellfish aquaculture and the environment. Wiley-Blackwell Science Publishers, Ames, IA, p 135-154

Gryska A, Parsons J, Shumway SE, Geib K, Emery I, Kuenster S (1996) Polyculture of sea scallops suspended from salmon cages. J Shellfish Res 15:481

Handå A, Min H, Wang X, Broch OJ, Reitan KI, Helge R, Olsen Y (2012) Incorporation of fish feed and growth of blue mussels (Mytilus edulis) in close proximity to salmon (Salmo salar) aquaculture: implications for integrated multi-trophic aquaculture in Norwegian coastal waters. Aquaculture 356-357:328-341

Hargrave BT (2010) Empirical relationships describing ben- 
thic impacts of salmon aquaculture. Aquacult Environ Interact 1:33-46

Hawkins AJS, Bayne BL, Bougrier S, Héral M and others (1998) Some general relationships in comparing the feeding physiology of suspension-feeding bivalve molluscs. J Exp Mar Biol Ecol 219:87-103

Hawkins AJS, James MR, Hickman RW, Hatton S, Weatherhead M (1999) Modelling of suspension-feeding and growth in the green-lipped mussel Perna canalicus exposed to natural and experimental variations of seston availability in the Marlborough Sounds, New Zealand. Mar Ecol Prog Ser 191:217-232

Herndl GJ, Reinthaler T (2013) Microbial control of the dark end of the biological pump. Nat Geosci 6:718-724

* Irisarri J, Cubillo AM, Fernández-Reiriz MJ, Labarta U (2013) Growth variations within a farm of mussel (Mytilus galloprovincialis) held near fish cages: importance for the implementation of integrated aquaculture. Aquacult Res 46:1988-2002

Irisarri J, Fernández-Reiriz MJ, Cranford PJ, Labarta U (2014) Effects of seasonal variations in phytoplankton on the bioenergetic responses of mussels (Mytilus galloprovincialis) held on a raft in the proximity of red sea bream (Pagellus bogaraveo) net-pens. Aquaculture 428429:41-53

Jiang Z, Wang G, Fang J, Mao Y (2013) Growth and food sources of Pacific oyster Crassostrea gigas integrated culture with sea bass Lateolabrax japonicus in Ailian Bay, China. Aquacult Int 21:45-52

Jones TO, Iwama GK (1991) Polyculture of the Pacific oyster, Crassostrea gigas (Thunberg), with Chinook salmon, Oncorhynchus tshawytscha. Aquaculture 92:313-322

Jusup M, Gecek S, Legovic T (2007) Impact of aquacultures on the marine ecosystem: modelling benthic carbon loading over variable depth. Ecol Model 200:459-466

Lander T, Barrington K, Robinson SMC, MacDonald B, Martin J (2004) Dynamics of the blue mussel as an extractive organism in an integrated aquaculture system. Bull Aquacult Assoc Can 104:19-28

Lander TR, Robinson SMC, MacDonald BA, Martin JD (2012) Enhanced growth rates and condition index of blue mussels (Mytilus edulis) held at integrated multitrophic aquaculture (IMTA) sites in the Bay of Fundy. J Shellfish Res 31:997-1007

Lander TR, Robinson SMC, MacDonald BA, Martin JD (2013) Characterization of the suspended organic particles released from salmon farms and their potential as a food supply for the suspension feeder, Mytilus edulis in integrated multi-trophic aquaculture (IMTA) systems. Aquaculture 406-407:160-171

Lefebvre S, Barille L, Clerc M (2000) Pacific oyster (Crassostrea gigas) feeding responses to a fish-farm effluent. Aquaculture 187:185-198

Liutkus M, Robinson SMC, MacDonald C, Reid G (2012) Quantifying the effects of diet and mussel size on the biophysical properties of the blue mussel, Mytilus spp., feces egested under simulated IMTA conditions. J Shellfish Res 31:69-77

MacDonald BA, Robinson SMC, Barrington KA (2011) Feeding activity of mussels (Mytilus edulis) held in the field at an integrated multi-trophic aquaculture (IMTA) site (Salmo salar) and exposed to fish food in the laboratory. Aquaculture 314:244-251

McDonnell AMP, Buesseler KO (2010) Variability in the average sinking velocity of marine particles. Limnol
Oceanogr 55:2085-2096

*Melbourne-Thomas J, Johnson CR, Fulton EA (2011) Characterizing sensitivity and uncertainty in a multiscale model of a complex coral reef system. Ecol Model 222: 3320-3334

Navarrete-Mier F, Sanz-Lázaro C, Marín A (2010) Does bivalve mollusc polyculture reduce marine fin fish farming environmental impact? Aquaculture 306:101-107

Nobre AM, Ferreira JG, Nunes JP, Yan X and others (2010) Assessment of coastal management options by means of multilayered ecosystem models. Estuar Coast Shelf Sci $87: 43-62$

Nunes JP, Ferreira JG, Gazeau F, Lencart-Silva J, Zhang XL, Zhu MY, Fang JG (2003) A model for sustainable management of shellfish polyculture in coastal bays. Aquaculture 219:257-277

* Parsons GJ, Shumway SE, Kuenstner S, Gryska A (2002) Polyculture of sea scallops (Placopecten magellanicus) suspended from salmon cages. Aquacult Int 10:65-77

Peharda M, Župan I, Bav evi L, Franki A, Klanjš ek T (2007) Growth and condition index of mussel Mytilus galloprovincialis in experimental integrated aquaculture. Aquacult Res 38:1714-1720

Pridmore RD, Rutherford JC (1992) Modelling phytoplankton abundance in a small enclosed bay used for salmon farming. Aquacult Fish Manag 23:525-542

Reid GK (2007) Nutrient releases from salmon aquaculture. In: Costa-Pierce B (ed) Nutrient impacts of farmed Atlantic salmon (Salmo salar) on pelagic ecosystems and implications for carrying capacity. World Wildlife Fund, Washington, DC, p 7-22

* Reid GK, Liutkus M, Robinson SMC, Chopin TR and others (2009) A review of the biophysical properties of salmonid faeces: implications for aquaculture waste dispersal models and integrated multi-trophic aquaculture. Aquacult Res 40:257-273

Reid GK, Liutkus M, Bennett A, Robinson SMC, MacDonald B, Page F (2010) Absorption efficiency of blue mussels (Mytilus edulis and M. trossulus) feeding on Atlantic salmon (Salmo salar) feed and fecal particulates: implications for integrated multi-trophic aquaculture. Aquaculture 299:165-169

Reid GK, Robinson SMC, Chopin T, MacDonald BA (2013a) Dietary proportion of fish culture solids required by shellfish to reduce the net organic load in open-water Integrated Multi-Trophic Aquaculture: a scoping exercise with cocultured Atlantic salmon (Salmo salar) and blue mussel (Mytilus edulis). J Shellfish Res 32:509-517

* Reid GK, Chopin T, Robinson SMC, Azevedo P, Quinton M, Belyea E (2013b) Weight ratios of the kelps, Alaria esculenta and Saccharina latissima, required to sequester dissolved inorganic nutrients and supply oxygen for Atlantic salmon, Salmo salar, in Integrated Multi-Trophic Aquaculture systems. Aquaculture 408-409:34-46

Ren JS, Stenton-Dozey J, Plew DR, Fang J, Gall M (2012) An ecosystem model for optimising production in integrated multitrophic aquaculture systems. Ecol Model 246:34-46

Rensel JE, Bright K, Siegrist Z (2011) Integrated fish-shellfish mariculture in Puget Sound. NOAA National Marine Aquaculture Initiative Award NA080AR4170860. Rensel Associates Aquatic Sciences, in association with American Gold Seafoods and Taylor Shellfish, Arlington, WA

Robinson SMC, Reid GK (2014) Review of the potential near-and far-field effects of the organic extractive component of integrated multi-trophic aquaculture (IMTA) in 
southwest New Brunswick with emphasis on the blue mussel (Mytilus edulis). Canadian Science Advisory Secretariat Research Document 2014/026, Department of Fisheries and Oceans Canada, Ottawa

Sarà G, Zenone A, Tomasello A (2009) Growth of Mytilus galloprovincialis (Mollusca, Bivalvia) close to fish farms: a case of integrated multi-trophic aquaculture in the Tyrrhenian Sea. Hydrobiologia 636:129-136

Sarà G, Lo Martire M, Sanflippo M, Pulicanò G and others (2011) Impacts of marine aquaculture at large spatial scales: evidences from $\mathrm{N}$ and $\mathrm{P}$ catchment loading and phytoplankton biomass. Mar Environ Res 71:317-324

Sarà G, Reid GK, Rinaldi A, Palmeri V, Troell M, Kooijman SALM (2012) Growth and reproductive simulation of candidate shellfish species at fish cages in the southern Mediterranean, dynamic energy budget (DEB) modelling for integrated multi-trophic aquaculture. Aquaculture 324-325:259-266

Soto D (2009) Integrated mariculture: a global review. FAO Fish Aquacult Tech Pap 529. FAO, Rome

Stigebrandt A (2011) Carrying capacity: general principles of model construction. Aquacult Res 42:41-50

Stirling HP, Okumus I (1995) Growth and production of mussels (Mytilus edulis L.) suspended at salmon cages and shellfish farms in two Scottish sea lochs. Aquaculture 134:193-210

Strain PM, Hargrave BT (2005) Salmon aquaculture, nutrient fluxes and ecosystem processes in southwestern New Brunswick. In: Hargrave BT (ed) Environmental effects of marine finfish aquaculture. Springer, Berlin, p 29-57

Taylor BE, Jamieson G, Carefoot TH (1992) Mussel culture

Editorial responsibility: Gianluca Sará,

Palermo, Italy in British Columbia: the influence of salmon farms on growth of Mytilus edulis. Aquaculture 108:51-66

Troell M, Norberg J (1998) Modelling of suspended solids in an integrated salmon-mussel culture. Ecol Model 110: 65-77

Tsagaraki TM, Petihakis G, Tsiaras K, Triantafyllou G and others (2011) Beyond the cage: ecosystem modeling for impact evaluation in aquaculture. Ecol Model 222: 2512-2523

United Nations, Department of Economic and Social Affairs, Population Division (2013) World population prospects: the 2012 revision, highlights and advance tables. ESA/ P/WP. 228. Available at esa.un.org/unpd (accessed on 13 June 2013)

*Wallace JC (1980) Growth rates of different populations of the edible mussel, Mytilus edulis, in north Norway. Aquaculture 19:303-311

Weldrick CK, Jelinski DE (2016) Resource subsidies from multi-trophic aquaculture affect isotopic niche width in wild blue mussels (Mytilus edulis). J Mar Syst 157: 118-123

*Wildish DJ, Hughes-Clarke JE, Pohle GW, Hargrave BT, Mayer LM (2004) Acoustic detection of organic enrichment in sediments at a salmon farm is confirmed by independent groundtruthing methods. Mar Ecol Prog Ser 267:99-105

Winter JE (1976) A critical review on some aspects of filterfeeding in lamellibranchiate bivalves. Haliotis 7:71-87

*Wu Y, Chaffey J, Law B, Greenberg DA, Drozdowski A, Page F, Haigh S (2014) A three-dimensional hydrodynamic model for aquaculture: a case study in the Bay of Fundy. Aquacult Environ Interact 5:235-248

Submitted: June 13, 2016; Accepted: December 28, 2016 Proofs received from author(s): February 18, 2017 